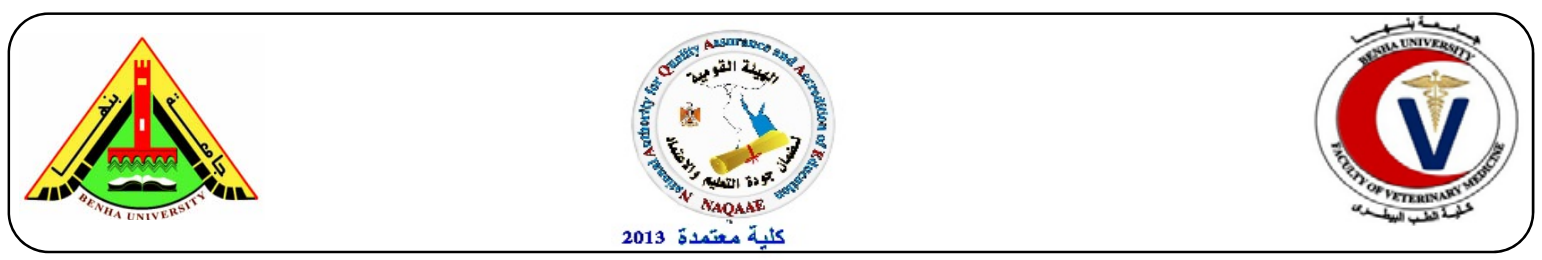

\title{
Biochemical alterations in erythrocytes membrane lipid in experimentally induced atherosclerosis and their modulation with chitosan in rats
}

\author{
Samy A. Hussein ${ }^{1}$, Omayma A.R. AboZaid ${ }^{1}$, Tahya E. A. Ismael ${ }^{2}$, Ghada F. Al lawaty ${ }^{1}$ \\ ${ }^{I}$ Department of Biochemistry, Faculty of Veterinary Medicine, Benha University. ${ }^{2}$ Department of \\ Nutrition \&Clinical Nutrition, Faculty of Veterinary Medicine, Benha University. Corresponding \\ author: E-mail: Samyaziza@yahoo.com
}

\section{A B S T R A C T}

Hypercholesterolemia is one of the most important risk factors for atherosclerosis and subsequent cardiovascular disease. In the present study, the therapeutic effect of chitosan administration on serum lipids profile, apolipoprotein A (apo A) and apolipoprotein B (apo B) in addition to Lipid composition in erythrocytes membrane [Total cholesterol (TC), and free fatty acids (FFA)] in hypercholesterolemia induced in rats have been evaluated. Sixty male rats were divided into four equal groups of 15 rats each. Group I (Control group): rats fed on normal diet. Group П: Rats fed on high cholesterol diet (HCD) [4\% cholesterol (w/w) and 1\% cholic acid]. Group III: Rats fed with HCD + Chitosan 5\% (5g/100g/day) after two weeks from the onset of the experiment (induction of hypercholesterolemia). Group IV: Rats fed with normal diet + Chitosan $5 \%(5 \mathrm{~g} / 100 \mathrm{~g} /$ day $)$. Blood samples were collected from all animal groups three times at 2, 4 and 6 weeks from the onset of treatment with chitosan. The obtained results showed a marked increase in serum total cholesterol, triacylglycerols, LDL-C, VLDL-C, phospholipids and Apo $\mathrm{B}$ concentration as well as in erythrocytes membrane lipids composition (TC and FFA) in hypercholesterolemia induced in rats. However, serum HDL-C and Apo A levels were significantly decreased. Treatment with chitosan to hypercholesterolemic induced rats lowered serum lipids and lipoproteins profile (LDL-C, VLDL-C), and erythrocytes lipids composition with increasing HDL-C and Apo A concentrations. These results suggest that, chitosan may be effective in controlling cholesterolemic status and improving dyslipidemia and has the potential in reducing cardiovascular complications due to hypercholesterolemia.

Keywords: Chitosan; Hypercholesterolemia; lipid profile; Apo A; Erythrocyte membrane lipids

(http://www.bvmj.bu.edu.eg)

(BVMJ-29(2): 36-46, 2015)

\section{INTRODUCTION}

$\mathrm{H}$ ypercholesterolemia is a condition characterized by very high levels of cholesterol in the blood. Hypercholesterolemia is one of the most important risk factors for atherosclerosis and subsequent cardiovascular disease (Steinberg, 2002). Hypercholesterolemia and Hyperlipidemia has been ranked as one of the greatest risk factors contributing to the prevalence and severity of coronary heart diseases. In developing countries, the incidence of cardiovascular disease is increasing alarmingly especially; India is on the verge of a cardiovascular epidemic
(Okrainec et al., 2004). Feeding animals with cholesterol has often been used to elevate serum or tissue cholesterol levels to study the etiology of hypercholesterolemiarelated metabolic disturbances (Bocan, 1998). Exogenous hypercholesterolemia causes fat deposition in the liver and depletion of the hepatocyte population; it can also cause malfunctioning of the liver, which apparently follows micro vesicular stenosis due to the intracellular accumulation of lipids (Assy et al., 2000). In addition, feeding cholesterol-rich diets induces free radical production (ROS), 
followed by oxidative stress and hypercholesterolemia (Bulur et al., 1995).

Chitosan, a polymer of glucosamine, can be defined both chemically and physiologically as a dietary fiber because it cannot be degraded by human digestive enzymes (Razdan and Pettersson,1996). Growing evidences indicate that chitosan can reduce serum and liver triglyceride (TG) and total cholesterol (TC) levels, exhibiting potent hypolipidemic activity(Liao et al., 2007; Xia et al., 2011). Maezaki et al. (1993) was the first to report the hypolipidemic effect of chitosan in human and found that chitosan effectively decreased serum lipid levels without side effects. Chitosan can reduce the risk of cardiovascular diseases.Also, chitosan had potent fat-binding capacity in vitro (Zhou et al., 2006). In addition, it was shown to increase fecal- neutral-steroid and bile-acid excretion in rats(Cho et al., 1998; Fukada et al., 1991; Sugano et al., 1980) and lower the post- prandial plasma TG level in broiler chickens (Razdan\&Pettersson, 1996). However, the mechanisms of the hypocholesterolemic and hypolipidemic effects of different chitosan remained unclear. Furthermore, chitosan has been suggested to reduce fat absorption from gastrointestinal tract by binding with anionic carboxyl groups of fatty and bile acids, and it interferes with emulsification of neutral lipids (i.e., cholesterol, other sterols) by binding them with hydrophobic bonds (Ylitalo et al. 2002). Accordingly, the purpose of the present study was to investigate the effect of chitosan against high cholesterol diet induced hypercholesterolemia and alterations in erythrocytes membrane lipids in rats. Also, to determine whether chitosan when administered to hypercholesterolemic induced-rats beneficial for prevention and treatment of hypercholesterolemia complications.

\section{MATERIALS AND METHODS}

\subsection{Experimental animals:}

Sixty male albino rats, $12-16$ weeks old and average body weight 150-180 g were used in the experimental investigation of this study. Rats were obtained from Laboratory Animals Research Center, Faculty of Veterinary Medicine, Moshtohor, Benha University. Animals were housed in separate metal cages, fresh and clean drinking water was supplied ad-libitum. Rats were kept at constant environmental and nutritional conditions throughout the period of experiment. The animals were left 14 days for acclimatization before the beginning of the experiment.

\subsection{Chitosan:}

Chitosan is Powder from crab shells poly(1-4- $\beta \mathrm{D}$-glucopyranosamine), 2-Amino-2deoxy $\beta$ D-glucopyranon (Cavalcanti et al., 2013). Chitosan was added to the basal diet at a dose $5 \%(1 \mathrm{~kg} \operatorname{diet} / 50 \mathrm{gm} /$ Chitosan $)$ according to (Zhang et al., 2008).

\subsection{Induction of Hypercholesterolemia:}

Hypercholesterolemia was induced in rat by feeding high cholesterol diet $[4 \%$ cholesterol (w/w) and $1 \%$ cholic acid $(\mathrm{w} / \mathrm{w})]$ (Kamesh and Sumathi, 2012).

\subsection{Design of the experimental work:}

Rats were randomly divided into four main equal groups, 15 rats each, placed in individual cages and classified as follow: Group 1: Control Normal group: Rats fed an ordinary diet only without any treatment during the entire experimental period of 8weeks. Group2: High cholesterol diet (HCD) group: Rats fed with hypercholesterolemic diet (HCD) [4\% cholesterol (w/w) and 1\% cholic acid] and received no drug all over the periods of the experiment. Group 3: High cholesterol diet (HCD) +chitosan treated group: Rats fed with $\mathrm{HCD}+$ chitosan 5\% (5g / 100g /day) after two weeks from the onset of the experiment (induction of hypercholesterolemia). Group 4: Normal chitosan group: Rats fed with normal diet + chitosan $5 \%(5 \mathrm{~g} / 100 \mathrm{~g} /$ day $)$ after two weeks from the onset of the experiment.

\subsection{Sampling:}


Random blood sample were collected from all animal's groups (control and experimental groups) three times along the duration of experiment after 2 weeks, 4 weeks and 6 weeks from the onset of treatment with chitosan.

\subsubsection{Blood samples:}

Blood samples for serum separation were collected by ocular vein puncture in dry, clean, and screw capped tubes and serum were separated by centrifugation at 2500r.p.m for 15 minutes and received in dry sterile samples tube by automatic pipette and kept in a deep freeze at $-20^{\circ} \mathrm{C}$ until used for subsequent biochemical analysis. All sera were analyzed for total cholesterol (TC), triacylglycerol (TAG), high density lipoprotein cholesterol (HDLC), low-density lipoprotein cholesterol (LDL-C), very low-density lipoprotein cholesterol (VLDL-C), phospholipids, apolipoprotein A (apo A) and apolipoprotein B (apo B).

\subsubsection{Isolation of membrane of erythrocytes:}

Another blood samples were collected in dry, clean, and screw capped tubes containing an anticoagulant solution, trisodium citrate $3.8 \%$ ( 1 vol. anticoagulant / 9 vol. blood) and plasma were separated by centrifugation at 2500 r.p.m for 15 minutes. Erythrocytes were washed twice with phosphate-buffered saline solution at $\mathrm{PH}$ 7.4. The washed erythrocytes were then suspended in $\mathrm{NaCl} 0.9 \%$ to provide a $50 \%$ hematocrit. Red cells were hemolyzed by placing $200 \mu \mathrm{l}$ of the erythrocyte suspension at $-20^{\circ} \mathrm{C}$ for 2 hours. Lipid extraction in erythrocyte membrane: About $5 \mathrm{ml}$ of isopropanol was added first to each tube, and the tubes were shaken vigorously. Sufficient anhydrous sodium sulfate was then added to remove the water. The mixture was vortexed for 2 minutes and then filtered or centrifuged at 3000 r.p.m. for 10 min (Peuchant et al., 1989). All lipid extraction samples were analyzed for the determination of Total cholesterol (TC) and free fatty acids (FFA).

\subsection{Biochemical analysis:}

Serum total cholesterol (TC), triacylglycerol (TAG), high density lipoprotein cholesterol (HDL-C), lowdensity lipoprotein cholesterol (LDL-C), very low-density lipoprotein cholesterol (VLDL-C), phospholipids, apolipoprotein A (apo A), apolipoprotein B (apo B) concentrations were analyzed according to the methods described by Ellefson and Caraway, (1976); Stein, (1987); National cholesterol Education program Recommendation for measurement of High-density Lipoprotein Cholesterol, (1995); Friedewald et al., (1972); Bauer, (1982); Takayama et al., (1977); Rat Apolipoprotein A1 (APOA1) ELISA (Kamiya Biomedical Company, Cat. No. KT-7354); Rat Apolipoprotein B (APO B) ELISA (Kamiya Biomedical Company, Cat. No. KT- 7394), respectively.

\subsection{Statistical analysis:}

The obtained data were statistically analyzed by one-way analysis of variance (ANOVA) followed by the Duncan multiple test. Allanalyses were performed using the statistical package for social science (SPSS, 13.0 software, 2009), values of $P<0.05$ were considered to be significant.

\section{RESULTS}

\subsection{Effect of chitosan administration on serum total cholesterol, triacylglycerol and phospholipids concentrations in normal and high cholesterol fed male rats:}

The obtained results demonstrated in table (1) revealed that, a non-significant increase in serum TC concentration was observed after 2 weeks followed by a significant increase after 4 and 6 weeks. Also, a significant increase in serum TAG and phospholipids concentrations were observed in cholesterol fed rats all over the period of the experiments when compared 
with rats fed normal control diet. Chitosan treatment in rats fed high cholesterol diet resulted in a non-significant decrease in serum TC and phospholipids concentrations after 2 weeks of the experiment, followed by a significant decrease after 4 and 6 weeks. Also, Chitosan treatment resulted in a significant decrease in serum TAG level all over the periods of the experiments as compared to untreated cholesterol -fed rats.

\subsection{Effect of chitosan administration on serum $H D L-c, L D L-c$ and $V L D L-c$ concentrations in normal and high cholesterol fed male rats:}

The obtained results in table (2) revealed that, serum LDL-c and VLDL-c concentrations were significantly increased and serum HDL-c level was significantly decreased in cholesterol fed rats all over the periods of the experiment when compared with rats fed normal control diet. Chitosan treatment in rats fed high cholesterol diet resulted in a significant decrease in serum LDL-c and VLDL-c levels all over the periods of the experiment as compared to untreated cholesterol -fed rats. On the other hand, a non-significant increase in serum HDL-c level was observed in Chitosan treated group after two weeks followed by a significant increase after four and six weeks as compared to untreated cholesterol -fed rats.

\subsection{Effect of chitosan administration on serum Apo A and Apo B concentrations in normal and high cholesterol fed male rats:}

The obtained results presented in table (3) showed a significant increase in serum Apo $B$ concentration with significant decrease in serum Apo A level in cholesterol fed rats all over the periods of the experiment when compared with rats fed normal control diet. Chitosan treatment in rats fed high cholesterol diet_resulted in a significant decrease in serum Apo B level. Meanwhile, a significant increase in serum Apo A concentration was observed all over the periods of the experiment as compared to untreated cholesterol -fed rats.

\subsection{Effect of chitosan administration on total cholesterol and free fatty acids concentrations of erythrocyte membrane in normal and high cholesterol fed male rats:}

A significant increase in total cholesterol concentration of erythrocyte membrane was observed in cholesterol fed rats after two and four weeks of the experiment. Also, a significant increase in free fatty acids concentration of erythrocyte membrane was observed all over the periods of the experiment when compared with rats fed normal control diet. Chitosan treatment in rats fed high cholesterol diet resulted in a significant decrease in total cholesterol concentration of erythrocyte membrane after two and four weeks followed by a nonsignificant decrease after sex weeks of the experiment. On the other hand, a nonsignificant decrease in free fatty acids concentration of erythrocyte membrane was observed all over the periods of the experiment as compared to untreated cholesterol-fed rats.

\section{DISCUSSION}

Hypercholesterolemia is the main risk factor of cardiovascular diseases such as atherosclerosis, myocardial infarction, stroke and cerebrovascular diseases which some of these diseases is the cause of death in industrial countries. These diseases are diagnosed through natural increasing of lipids (triglycerides and cholesterol) and lipoprotein in blood (Maruthappan and Shree, 2010). The obtained results demonstrated in (Tables 1 and 2) revealed that, a significant increase in serum lipids profile were observed in group of rats fed high cholesterol diet. Cholesterol-cholic acid feeding has often been used to raise cholesterol levels in plasma and tissues of experimental animals (Chen et al., 2004). It has been shown by other investigators that an increase in dietary cholesterol intake in 
Table (1): Effect of chitosan administration on serum total cholesterol, triacylglycerol and phospholipids concentrations in normal and high cholesterol diet induced hypercholesterolemia in male rats.

\begin{tabular}{|c|c|c|c|c|c|c|c|c|c|}
\hline \multirow{2}{*}{$\begin{array}{l}\text { Parameters } \\
\text { Exp. } \\
\text { Groups }\end{array}$} & \multicolumn{3}{|c|}{ Total Cholesterol (mg/dl) } & \multicolumn{3}{|c|}{ Triacylglycerol (mg/dl) } & \multicolumn{3}{|c|}{ Phospholipids (mg/dl) } \\
\hline & $\begin{array}{c}2 \\
\text { Weeks }\end{array}$ & $\begin{array}{c}4 \\
\text { Weeks }\end{array}$ & $\begin{array}{c}6 \\
\text { Weeks }\end{array}$ & $\begin{array}{c}2 \\
\text { Weeks }\end{array}$ & $\begin{array}{c}4 \\
\text { Weeks }\end{array}$ & $\begin{array}{c}6 \\
\text { Weeks }\end{array}$ & $\begin{array}{c}2 \\
\text { Weeks }\end{array}$ & $\begin{array}{c}4 \\
\text { Weeks }\end{array}$ & $\begin{array}{c}6 \\
\text { Weeks }\end{array}$ \\
\hline $\begin{array}{l}\text { Normal } \\
\text { control }\end{array}$ & $\begin{array}{c}63.35 \pm \\
2.60^{\mathrm{a}}\end{array}$ & $\begin{array}{c}78.42 \pm \\
0.42^{\mathrm{b}}\end{array}$ & $\begin{array}{l}85.77 \pm \\
2.43^{\mathrm{b}, \mathrm{c}}\end{array}$ & $\begin{array}{c}83.65 \pm \\
1.23^{\mathrm{c}}\end{array}$ & $\begin{array}{c}86.80 \pm \\
1.35^{\mathrm{b}}\end{array}$ & $\begin{array}{l}88.51 \pm \\
0.93^{\mathrm{a}, \mathrm{b}, \mathrm{c}}\end{array}$ & $\begin{array}{c}66.56 \pm \\
1.07^{c}\end{array}$ & $\begin{array}{c}72.62 \pm \\
2.78^{\mathrm{b}}\end{array}$ & $\begin{array}{r}79.13 \pm \\
6.31^{\mathrm{c}, \mathrm{d}}\end{array}$ \\
\hline $\begin{array}{c}\text { High } \\
\text { cholesterol } \\
\text { diet }\end{array}$ & $\begin{array}{c}79.97 \pm \\
2.50^{\mathrm{a}}\end{array}$ & $\begin{array}{c}96.89 \pm \\
10.39^{\mathrm{a}}\end{array}$ & $\begin{array}{c}111.68 \pm \\
5.98^{\mathrm{a}}\end{array}$ & $\begin{array}{c}117.62 \pm \\
6.00^{\mathrm{a}}\end{array}$ & $\begin{array}{c}121.01 \pm \\
9.09^{\mathrm{a}}\end{array}$ & $\begin{array}{c}111.59 \pm \\
7.71^{\mathrm{a}}\end{array}$ & $\begin{array}{c}102.60 \pm \\
9.19^{\mathrm{a}}\end{array}$ & $\begin{array}{c}108.47 \pm \\
5.89^{\mathrm{a}}\end{array}$ & $\begin{array}{c}120.59 \pm \\
1.67^{\mathrm{a}}\end{array}$ \\
\hline Chitosan & $77.57 \pm$ & $66.95 \pm$ & $65.37 \pm$ & $95.87 \pm$ & $79.40 \pm$ & $84.37 \pm$ & $91.89 \pm$ & $73.62 \pm$ & $74.65 \pm$ \\
\hline Treated & $5.35^{\mathrm{a}}$ & $2.91^{\mathrm{b}}$ & $6.70^{\mathrm{c}, \mathrm{d}}$ & $3.64^{b, c}$ & $5.18^{\mathrm{b}}$ & $7.08^{b, c}$ & $10.67^{\mathrm{a}, \mathrm{b}, \mathrm{c}}$ & $5.51^{\mathrm{b}}$ & $6.08^{\mathrm{c}, \mathrm{d}}$ \\
\hline Chitosan & $79.75 \pm$ & $75.80 \pm$ & $87.83 \pm$ & $85.60 \pm$ & $83.83 \pm$ & $73.49 \pm$ & $94.42 \pm$ & $74.51 \pm$ & $64.83 \pm$ \\
\hline Normal & $9.41^{\mathrm{a}}$ & $2.59^{\mathrm{b}}$ & $2.83^{\mathrm{b}}$ & $9.36^{\mathrm{c}}$ & $3.78^{\mathrm{b}}$ & $12.43^{\mathrm{c}}$ & $5.17^{\mathrm{a}, \mathrm{b}}$ & $8.41^{\mathrm{b}}$ & $3.04^{\mathrm{d}}$ \\
\hline
\end{tabular}

Data are presented as (Mean \pm S.E). S.E $=$ Standard error. Mean values with different superscript letters in the same column are significantly different at $(P \leq 0.05)$.

Table (2): Effect of chitosan administration on serum HDL-c, LDL-c and VLDL-c concentrations in normal and high cholesterol diet induced hypercholesterolemia in male rats.

\begin{tabular}{cccccccccc}
\hline Parameter & \multicolumn{3}{c}{ HDL-c (mg/dl) } & \multicolumn{3}{c}{ LDL-c (mg/dl) } & \multicolumn{3}{c}{ VLDL-c (mg/dl) } \\
s & & & & & & & & & \\
Exp. & 2 & 4 & 6 & 2 & 4 & 6 & 2 & 4 & 6 \\
Groups & Week & Week & Week & Weeks & Weeks & Weeks & Weeks & Weeks & Weeks \\
& $\mathrm{s}$ & $\mathrm{s}$ & & & & & & & \\
\hline Normal & 39.62 & 47.29 & 49.95 & $83.65 \pm$ & $86.80 \pm$ & $88.51 \pm$ & $66.56 \pm$ & $72.62 \pm$ & $79.13 \pm$ \\
control & \pm & \pm & \pm & $1.23^{\mathrm{c}}$ & $1.35^{\mathrm{b}}$ & $0.93^{\mathrm{a}, \mathrm{b}, \mathrm{c}}$ & $1.07^{\mathrm{c}}$ & $2.78^{\mathrm{b}}$ & $6.31^{\mathrm{c}, \mathrm{d}}$ \\
& $0.75^{\mathrm{a}, \mathrm{b}}$ & $1.05^{\mathrm{a}, \mathrm{b}}$ & $2.44^{\mathrm{a}, \mathrm{b}}$ & & & & & & \\
& & & & & & & & & \\
High & 32.93 & 34.14 & 37.18 & 117.62 & 121.01 & 111.59 & 102.60 & 108.47 & 120.59 \\
cholestero & \pm & \pm & \pm & \pm & \pm & \pm & \pm & \pm & \pm \\
1 diet & $1.43^{\mathrm{b}}$ & $0.94^{\mathrm{c}}$ & $0.21^{\mathrm{c}}$ & $6.00^{\mathrm{a}}$ & $9.09^{\mathrm{a}}$ & $7.71^{\mathrm{a}}$ & $9.19^{\mathrm{a}}$ & $5.89^{\mathrm{a}}$ & $1.67^{\mathrm{a}}$ \\
& & & & & & & & & \\
Chitosan & 52.09 & 40.02 & 42.95 & $95.87 \pm$ & $79.40 \pm$ & $84.37 \pm$ & $91.89 \pm$ & $73.62 \pm$ & $74.65 \pm$ \\
Treated & \pm & \pm & \pm & $3.64^{\mathrm{b}, \mathrm{c}}$ & $5.18^{\mathrm{b}}$ & $7.08^{\mathrm{b}, \mathrm{c}}$ & $10.67^{\mathrm{a}, \mathrm{b},}$ & $5.51^{\mathrm{b}}$ & $6.08^{\mathrm{c}, \mathrm{d}}$ \\
& $6.67^{\mathrm{a}}$ & $2.00^{\mathrm{b}, \mathrm{c}}$ & $4.66^{\mathrm{b}, \mathrm{c}}$ & & & & $c$ & & \\
Chitosan & 54.72 & 48.03 & 54.49 & $85.60 \pm$ & $83.83 \pm$ & $73.49 \pm$ & $94.42 \pm$ & $74.51 \pm$ & $64.83 \pm$ \\
Normal & \pm & \pm & \pm & $9.36^{\mathrm{c}}$ & $3.78^{\mathrm{b}}$ & $12.43^{\mathrm{c}}$ & $5.17^{\mathrm{a}, \mathrm{b}}$ & $8.41^{\mathrm{b}}$ & $3.04^{\mathrm{d}}$ \\
& $7.89^{\mathrm{a}}$ & $0.97^{\mathrm{a}, \mathrm{b}}$ & $3.55^{\mathrm{a}}$ & & & & & & \\
\hline
\end{tabular}

Data are presented as (Mean \pm S.E). S.E $=$ Standard error. Mean values with different superscript letters in the same column are significantly different at $(P \leq 0.05)$. 
Table (3): Effect of chitosan administration on serum Apo A1 and Apo B concentrations in normal and high cholesterol diet induced hypercholesterolemia in male rats.

\begin{tabular}{|c|c|c|c|c|c|c|}
\hline \multirow{2}{*}{$\begin{array}{l}\text { Parameters } \\
\text { Exp.Groups }\end{array}$} & \multicolumn{3}{|c|}{ Apo A1 (Pg/ml) } & \multicolumn{3}{|c|}{ Apo B (ng/ml) } \\
\hline & $\begin{array}{c}2 \\
\text { Weeks }\end{array}$ & $\begin{array}{c}4 \\
\text { Weeks }\end{array}$ & $\begin{array}{c}6 \\
\text { Weeks }\end{array}$ & $\begin{array}{c}2 \\
\text { Weeks }\end{array}$ & $\begin{array}{c}4 \\
\text { Weeks }\end{array}$ & $\begin{array}{c}6 \\
\text { Weeks }\end{array}$ \\
\hline Normal control & $\begin{array}{c}17.74 \pm \\
1.50^{\mathrm{a}}\end{array}$ & $\begin{array}{c}20.45 \pm \\
1.38^{\mathrm{a}}\end{array}$ & $\begin{array}{c}16.68 \pm \\
1.01^{\mathrm{a}}\end{array}$ & $\begin{array}{c}0.71 \pm \\
0.10^{\mathrm{b}}\end{array}$ & $\begin{array}{c}0.74 \pm \\
0.09^{b}\end{array}$ & $\begin{array}{c}0.64 \pm \\
0.03^{\mathrm{b}}\end{array}$ \\
\hline High cholesterol diet & $\begin{array}{c}10.56 \pm \\
1.23^{c}\end{array}$ & $\begin{array}{c}12.64 \pm \\
0.88^{\mathrm{c}}\end{array}$ & $\begin{array}{c}12.37 \pm \\
1.22^{\mathrm{b}}\end{array}$ & $\begin{array}{l}1.46 \pm \\
0.27^{\mathrm{a}}\end{array}$ & $\begin{array}{l}1.16 \pm \\
0.05^{\mathrm{a}}\end{array}$ & $\begin{array}{l}1.38 \pm \\
0.28^{\mathrm{a}}\end{array}$ \\
\hline Chitosan Treated & $\begin{array}{l}15.01 \pm \\
0.32^{\mathrm{a}, \mathrm{b}}\end{array}$ & $\begin{array}{c}16.96 \pm \\
0.12^{\mathrm{b}}\end{array}$ & $\begin{array}{c}15.69 \pm \\
0.62^{\mathrm{a}}\end{array}$ & $\begin{array}{c}0.87 \pm \\
0.11^{\mathrm{b}}\end{array}$ & $\begin{array}{c}0.64 \pm \\
0.38^{b}\end{array}$ & $\begin{array}{c}0.73^{ \pm} \\
0.17^{\mathrm{b}}\end{array}$ \\
\hline Chitosan Normal & $\begin{array}{c}17.37 \pm \\
1.17^{\mathrm{a}}\end{array}$ & $\begin{array}{c}18.40 \pm \\
0.98^{\mathrm{a}, \mathrm{b}}\end{array}$ & $\begin{array}{l}14.36 \pm \\
1.26^{\mathrm{a}, \mathrm{b}}\end{array}$ & $\begin{array}{c}0.65 \pm \\
0.12^{b}\end{array}$ & $\begin{array}{c}0.69 \pm \\
0.08^{\mathrm{b}}\end{array}$ & $\begin{array}{l}0.62 \pm \\
0.03^{\mathrm{b}}\end{array}$ \\
\hline
\end{tabular}

Data are presented as (Mean \pm S.E). S.E $=$ Standard error. Mean values with different superscript letters in the same column are significantly different at $(P \leq 0.05)$.

Table (4): Effect of chitosan administration on total cholesterol and triacylglycerol concentrations of erythrocyte membrane in normal and high cholesterol diet induced hypercholesterolemia in male rats $\left(\mu \mathrm{mol} / 10^{11}\right.$ red cells $)$.

\begin{tabular}{lcccccc}
\hline \multicolumn{1}{c}{ Parameters } & \multicolumn{3}{c}{ Total Cholesterol } & \multicolumn{2}{c}{ Free Fatty acids } \\
& $\begin{array}{c}4 \\
\text { Exp. Groups }\end{array}$ & Weeks & Weeks & $\begin{array}{c}6 \\
\text { Weeks }\end{array}$ & $\begin{array}{c}2 \\
\text { Weeks }\end{array}$ & $\begin{array}{c}\text { Weeks } \\
\text { Weeks }\end{array}$ \\
\hline Normal & $5.04 \pm$ & $2.85 \pm$ & $2.85 \pm$ & $2.85 \pm$ & $5.57 \pm$ & $8.55 \pm$ \\
control & $3.44^{\mathrm{b}}$ & $0.60^{\mathrm{b}}$ & $0.60^{\mathrm{b}}$ & $0.60^{\mathrm{b}}$ & $0.95^{\mathrm{b}}$ & $0.84^{\mathrm{b}}$ \\
High & $7.57 \pm$ & $15.12 \pm$ & $15.12 \pm$ & $15.12 \pm$ & $15.90 \pm$ & $20.97 \pm$ \\
cholesterol & $1.18^{\mathrm{a}}$ & $1.70^{\mathrm{a}}$ & $1.70^{\mathrm{a}}$ & $1.70^{\mathrm{a}}$ & $1.05^{\mathrm{a}}$ & $2.20^{\mathrm{a}}$ \\
diet & & & & & & \\
Chitosan & $3.41 \pm$ & $13.52 \pm$ & $13.52 \pm$ & $13.52 \pm$ & $14.74 \pm$ & $18.61 \pm$ \\
Treated & $0.62^{\mathrm{b}, \mathrm{c}}$ & $2.14^{\mathrm{a}}$ & $2.14^{\mathrm{a}}$ & $2.14^{\mathrm{a}}$ & $1.37^{\mathrm{a}}$ & $2.58^{\mathrm{a}}$ \\
Chitosan & $1.71 \pm$ & $3.95 \pm$ & $3.95 \pm$ & $3.95 \pm$ & $5.75 \pm$ & $9.29 \pm$ \\
Normal & $0.54^{\mathrm{c}}$ & $1.26^{\mathrm{b}}$ & $1.26^{\mathrm{b}}$ & $1.26^{\mathrm{b}}$ & $1.42^{\mathrm{b}}$ & $1.10^{\mathrm{b}}$ \\
\hline
\end{tabular}

Data are presented as (Mean \pm S.E). S.E $=$ Standard error. Mean values with different superscript letters in the same column are significantly different at $(P \leq 0.05)$

animals led to hypercholesterolemia (Kishida et al., 2002). The high levels of TAG in the present study may be due to inhibition of $7 \alpha$-hydroxylase activity (Beigneux et al., 2002). Also, the high levels of LDL-C found in hypercholesterolemic rats, may be attributed to a down regulation in LDL receptors by cholesterol and saturated fatty acids included in the diet (Mustad et al., 1997). Moreover, such increase in LDL-c level after high fat diet consumption might be explained via involvement of two enzymes namely cholesterol ester 
hydrolase and cholesterol ester synthetase. These enzymes balance the cholesterol levels in the blood. Hence, it is logical to assume that the elevation in plasma cholesterol is mediated through increased cholesterol turnover and influenced by the relative balance between cholesterol ester hydrolase and cholesterol ester synthetase activities. With increased esterifying activity (when cholesterol ester hydrolase: cholesterol ester synthetase is lowered) cholesterol will be predominantly in its ester form (as in LDL-c) and can lead to the development and progression of atherosclerosis (Shanmugasundaram et al., 1986).

The obtained results presented in (Tables 1 and 2) revealed that, chitosan treatment in rats fed high cholesterol diet resulted in marked decrease of serum lipids profile. Similarly, Qin and Tian, (2010) reported that, the significant decrease in lipid profile may be due to Chitosan was interact with oil, which inhibited duodenal absorption and enhanced lipid excretion and the regulation of excessive lipid synthesis and uptake is thought to be an effective intervention for Nonalcoholic fatty liver disease (NAFLD). Thus, lipid-lowering agents are promising pharmacological therapies for hepatic steatosis (Zeng et al., 2008). However, Maha et al., (2011); Pawel et al., (2007) revealed that, the first mechanism the positive charges on Chitosan attract the negatively charged fatty acids and bile acids binding them to the indigestible chitosan fiber. This mechanism can explain why Chitosan reduces LDL cholesterol levels. Our bodies make bile acids in the liver using the cholesterol from LDL. When Chitosan binds bile acids it increases the rate of LDL loss thus improving the LDL to HDL ratio. If enough bile acids are bound, the fats are not solubilized, which prevents their digestion and absorption. The second mechanism describes a netting effect of Chitosan fiber. In this model the Chitosan wraps around fat droplets and prevents their being attacked and digested by lipid enzymes. Fats unprotected by Chitosan are digested and absorbed. The "netting" mechanism has been seen to operate in vivo. Substances that enhance the action of chitosan fibers can be likened to a tangled-up chain. Fibers must "unravel" in order for them to be of maximum benefit to us. "Unraveling" is especially critical for chitosan because each link has a hook on which to attach lipids. A significant increase in serum Apo B was observed in cholesterol fed rats all over the periods of the experiments (Table 3 ). In present study, increased level of Apo B in high cholesterol feeding diet may be due to decreased expression of LDL-receptor during hyper-cholesterolemia induction. Decreased level of LDL-receptor is responsible for decreased clearance of apo B along with LDL, so these apolipoproteins are accumulated in the body (Ouguerram et al., 2004). However, most of the studies suggested that one molecule of Apo B exists per lipoprotein particle, thus the quantity of Apo B in fasting plasma predicts the number of LDL and VLDL particles (Levinson and Wagner, 1992). Therefore, plasma Apo B levels maybe a better assay of the concentration of atherogenic lipoprotein particles than total or LDL cholesterol levels (Sniderman and Silberberg, 1990). Abnormalities in the Apo B metabolism are responsible for the generation of hypercholesterolemia and increased risk of coronary heart disease (Whitfield et al., 2004).

Apo A plays a key role in the metabolism of HDL-cholesterol, which is esterified in the blood stream by lecithin cholesterol acetyltransferase, using Apo A as a cofactor, and then returns to the liver for excretion as bile acids or redistribution to other tissues, since high levels of Apo A are accompanied by high concentrations of the oxidation-resistant HDL, Apo A is thought to be a marker of adequate antiatherogenic defense. By contrast, apo B is associated with the LDL, which plays a central role in the uptake of cholesterolrich LDL particles by peripheral tissues and liver. A high concentration of LDL 
(and therefore of apo B), is atherogenic, since it is ingested by macrophages, thus producing foamy cells (Hashimoto et al., 2000). LDL is also involved in other pathological processes such as upregulation of adhesion molecule expression, attachment to endothelial cells, migration and sub-endothelial localization of macrophages, recruitment of smooth muscle cells and platelet activation, with resulting risk of thrombosis (Witting et al., 1999).

A significant increase in total cholesterol and free fatty acids concentrations of erythrocyte membrane were observed in high cholesterol fed rats all over the periods of the experiments (Table 4). Hyperlipidaemic conditions such as those encountered either during continued intake of atherogenic diets or the one found in poorly controlled diabetes mellitus is believed to affect the fluidity of red blood cells (RBC; Cazana et al. 1990). Similarly, Kempaiah\& Srinivasan, (2002) reported that, in rats rendered hypercholesterolaemic by maintaining them on a cholesterolenriched diet, as a result of alteration in the membrane cholesterol: phospholipid ratio, the structural integrity of RBC was also affected as indicated by increased osmotic fragility. Moreover, Kempaiah and Srinivasan (2005) reported that, in rats rendered hypercholesterolaemic by maintaining them on a cholesterol-enriched diet $(0.5 \%)$ for 8 weeks, as a result of alteration in membrane structural lipids, erythrocytes were observed to be deformed and become more fragile. Who added that, a further insight into the factors that might have reduced the fluidity of erythrocytes in hypercholesterolaemic rats revealed changes in fatty acid profile of the membranes, phospholipid composition of the membrane bilayer, reduced $\mathrm{Ca}^{2+}, \mathrm{Mg}^{2+}$ ATPase, and reduction in the sensitivity of erythrocytes to concanavaline A. Dietary capsaicin appeared to counter these changes partially in hypercholesterolaemic rats (Kempaiah and Srinivasan 2005). When there is an alteration in membrane lipid composition, a change in membrane properties is to be expected. Membrane abnormalities include increased fragility of erythrocytes, or else increased resistance to osmotic lysis, reduced activity of acetylcholinesterase, and increased activity content of ouabain-sensitive $\mathrm{Na}, \mathrm{K}$ ATPase. Osmotic fragility is a determinant of the deformability property of erythrocytes, which is essential for their function and survival against destruction by the spleen. Chitosan treatment in rats fed high cholesterol diet resulted in a significant decrease in total cholesterol concentration of erythrocyte membrane after two and four weeks of the experiments and non-significantly decrease free fatty acids concentration of erythrocyte membrane. Dietary chitosan appeared to correct this increased fragility of erythrocytes. As confirmed by (Kempaiah\& Srinivasan, 2002) who previously observed beneficial effect of dietary capsaicin on the osmotic fragility of erythrocytes of hypercholesterolaemic rats may thus be attributable to the partial restoration of the membrane phospholipid and fatty acid profile by capsaicin.

\section{Conclusion:}

Chitosan administration produces potent anti-atherogenic and an effective treatment against hypercholesterolemia and oxidative stress induced by high cholesterol diet in rats, since chitosan was able to ameliorate serum biochemical parameters, lipid profile, and endothelial function. We recommended that, administration of diet rich in the natural antioxidant is very important for protection of different body tissue, against oxidative stress or hypercholesterolemia and cardiac vascular disease and may be beneficial for patients who suffer from hyperlipidemia, hypercholesterolemia and/or arteriosclerosis.

\section{REFERENCES}

Assy, N., Kaita, K., Mymin, D., Levy, C., Rosser, B., Minuk, G. 2000. Fatty 
infiltration of liver in hyperlipidemic patients. Dig. Dis. Sci. 45: 1929-1934.

Bauer, J. D. 1982. "Clinical laboratory methods" 9th Ed, the C.V. Company Waistline Industrial Missouri 63116 Chapter 33, p.555.

Beigneux, A., Hofmann, A.F., Young, S.G. 2002. Human CYP7A1 deficiency: progress and enigmas. $J$ Clin Invest. 110:29-31.

Bocan, T.M. 1998. Animal models of atherosclerosis and interpretation of drug intervention studies. Curr. Pharm. Des. 4: 37-52.

Bulur, H., Ozdemirler, G., Oz, B., Toker, G., Ozturk, M., Uysal, M. 1995. High cholesterol diet supplemented with sunflower seed oil but not olive oil stimulates lipid peroxidation in plasma, liver, and aorta of rats. J. Nut. Biochem. 6: 547-550.

Cazana, F.J.D., Puyol, M.R., Caballero, J.P., Jimenez, A.J., Duarte, A.M. 1990. Effect of dietary hyperlipidemiahypercholesterolemia on rat erythrocytes. Int J Vit Nutr Res 60, 393-397.

Chen, W., Matuda, K., Nishimura, N., Yokogoshi, H. 2004. The effect of taurine on cholesterol degradation in mice fed a high-cholesterol diet. Life Sci, 74:1889-1898.

Cho, Y.I., No, H.K., Meyers, S.P. 1998. Physicochemical characteristics and functional properties of various commercial chitin and chitosan products. Journal of Agricultural and Food Chemistry, 46:3839e3843.

Ellefson, R.D., Caraway, W.T. 1976.fundamentals of clinical chemistry. EdTietz NW; p506.

Friedewald, W.T., Levy, R.I., Frederickson, D.S. 1972. Estimation of the concentration of low density lipoprotein cholesterol in plasma without use of the preparative ultracentrifuge. Clin Chem. 18(6):499502.

Fukada, Y., Kimura, K., Ayaki, Y. 1991. Effect of chitosan feeding on intestinal bile acid metabolism in rats. Lipids, 26 : (395e) 939.

Hashimoto, R., Narita, S., Yamadda, Y., Tanaka, K., Kojo, S. 2000. Unusually high reactivity of apolipoprotein B-100 among proteins to radical reactionsinduced in human plasma. Biochem. Biophys. Acta 483:236-240.

Kamesh, V.K., Sumathi, T. 2012. "Antihypercholesterolemic effect of Bacopamonniera linn. On high cholesterol diet induced hypercholesterolemia in rats," Asian Pacific Journal of Tropical Medicine, vol. 5, no. 12: pp. 949-955.

Kempaiah, R.K., Srinivasan, K. 2002. Integrity of erythrocytes of hypercholesterolemic rats during spices treatment. Mol Cell Biochem 236, 155-161.

Kempaiah, R.K., Srinivasan, K. 2005. Influence of dietary spices on the fluidity of erythrocytes in hypercholesterolaemic rats. British Journal of Nutrition 93, 81-91.

Kishida, T., Nogami, H., Ogawa, H., Ebihara, K. 2002. The hypocholesterolemic effect of high amylase corn starch in rats is mediated by an enlarged bile acid pool and increased fecal bile acid excretion, not by cecal fermented products. J. Nutr., 132: 2519-2524.

Levinson, S.S., Wagner, S.G. 1992. Measurement of apolipoprotein B containing lipoproteins for routine clinical laboratory use in cardiovascular disease. ArchPathol Lab Med. 116:1350-1354.

Liao, F.H., Shieh, M.J., Chang, N.C., Chien, Y.W. 2007. Nutrition Research 27:146-151.

Maezaki, Y., Tsuji, K., Nakagawa, Y., Kawai, Y., Akimoto, M., Tsugita, T., Takekawa, W., Terada, A., Hara, H., Mitsuoka, T. 1993. Bioscience, Biotechnology, and Bio- chemistry 57:1439-1444.

Maha, M., Mohamed, AsmaaFahmy.2011. Effects of Chitosan and Wheat Bran on 
Serum Leptin, TNF- $\alpha$, Lipid Profile and Oxidative Status in Animal Model of Non-Alcoholic Fatty Liver., Australian Journal of Basic and Applied Sciences, 5(10): 1478-1488, ISSN 1991-8178. Home Economic Dept., Women's College, Ain Shams University, Asmaa Fahmy St. Masr ElGededa Cairo,1478): Cairo, Egypt.

Maruthappan, V.G., Shree, K.S. 2010.Blood cholesterol lowering effect of adenantherapavonina seed extract on atherogenic diet induced hyperlipidemia in rats. Int $\mathbf{J}$ Pharm Sci Res; 1(7):87-94.

Mustad, V.A., Etherton, T.D., Cooper, A.D., Mastro, A.M., Pearson, T.A., Jonnalagadda, S.S., Kris-Etherton, P.M. 1997. Reducing saturated fat intake is associated with increased levels of LDL-receptors on mononuclear cells in healthy men and women. J. Lipid Res., 38: 459-468.

National Cholesterol Education program Recommendation 1995. Measurement of High- Density Lipoprotein Cholesterol: Executive Summary. ClinChem. 41:1427-1433.

Okrainec, K., Banerjee, D.K., Eisenberg, M.J. 2004.Coronary artery disease in the developing world. Am. Heart $J$. 148: 7-15.

Ouguerram, K., Chetiveaux, M., Zair, Y., Costet, P., Abifadel, M., Varret, M., Boileau, C., Magot, T., Krempf, M. 2004. Apolipoprotein B metabolism in autosomal-dominant hypercholesterolemia related to mutations in PCSK9. Arterioscler Thromb VascBiol. 24:1448-1453.

Paweł, W., Barbara, K., Katarzyna, H.W. 2007. Chitosan as a Lipid Binder a Langmuir Monolayer Study of Chitosan-Lipid Interactions. Faculty of Chemistry, Jagiellonian University, 30-060 Kraków, Ingardena 3, poland. Biomacro-molecules. 8 (8): pp 2611 2617.

Peuchant, E., Wolff, R., Salles, C., Jensen, R., 1989. One-step extraction of human erythrocyte lipids allowing rapid determination of fatty acid composition. Anal. Biochem., 181: 341- 344.

Qin, Y., Tian. 2010. Preventive effects of chronic exogenous growth hormone levels on diet-induced hepatic steatosis in rats. Lipids in Health and Disease, 9:78.

Razdan, A., pettersson, D. 1996. Hypolipidaemic, gastrointestinal and related responses of broiler chickens to chitosan of different viscosity. Br J Nutr;76: 387-397.

Shanmugasundaram, K.R., Visvanathan, A., Dhandapani, K., Srinivasan, N., Rasappan, P., Gilbert, R., Alladi, S., Kancharla, S., Vasanthi, N. 1986. Effect of high-fat diet on cholesterol distribution in plasma lipoproteins, cholesterol esterifying activity in leucocytes, and erythrocyte membrane components studied: importance of body weight, The American Journal of Clinical Nutrition, 44(6):805-815.

Sniderman, A.D., Silberberg, J. 1990. Is it time to measure apolipoprotein B? Atherosclerosis. 10:665-677.

Stein, E.A. 1987. Lipids, lipoproteins, and apolipoproteins. In NW Tietz, ed. Fundamentals of clinical chemistry, 3rd ed. Philadelphia: WB Saunders; 448.

Steinberg, D. 2002. Atherogenesis in perspective: hypercholesterolemia and inflammation as partners in crime. Nat. Med; 8: 1211-1217.

Sugano, M., Fujikawa, T., Hiratsuji, Y., Nakashima, K., Fukuda, N., Hasegawa Y. 1980.A novel use of chitosan as a hypocholesterolemic agent in rats. American Journal of Clinical Nutrition; 33:787 - 93 .

Takayama, M.,Itoh, S., Nagasaki, T., Tanimizu, I. 1977. A New Enzymatic Method for Determination of Serum Choline-Containing Phospholipids, Clin. Chim.Acta.15; 79(1):93-98.

Vogel, A. J. 1975.A text book of practical original chemistry. $3^{\text {rd }} \mathrm{Ed}$, pp. 969-971, 
English Language Book Society and Longman Group Ltd. London.

Whitfield, A.J., Barrett, H.R., VanBockxmeer, F.M., Burnett, J.R. 2004.Lipid disorders and mutations in the apo B gene.Clin Chem. 50:17251732.

Witting, P.K., Pettersson, K., OstlundLindqvist, A.M. 1999. Inhibition by a coantioxidant of aortic lipoprotein lipid peroxidation and atherosclerosis in apolipoprotein E and low density lipoprotein receptor gene double knockout mice. FASEB J. 13: 667-675.

Xia, W., Liu, P., Zhang, J., Chen, J. 2011.Food Hydrocolloids 25:170-179.

Ylitalo, R., S. Lehtinen, E.Wuolijoki, P. Ylitalo, and T. Lehtima"ki. 2002. Cholesterol-lowering properties and safety of chitosan. Arzneimittelforschung 52:1-7. (In German)

Zeng, L., Qin, C., Guanghui, W., Li, W., $\mathrm{Xu}, \mathrm{D} .2008$. Effect of dietary chitosans on trace iron, copper, zinc in mice. Carbohydrate Polymers, 74 (2): 27982.

Zhang, J., Liu, J., Li, L., Xia, E.2008.Dietary chitosan improveshypercholesterolemia in rats fed high fat diets. Nutr. Res., 28: 383390.

Zhou, K., Xia, W., Zhang, C., Yu, L. 2006. In vitro binding of bile acids and triglycerides by selected chitosan preparations and their physicochemical properties.LWT-Food Sci. Technol., 39: 1087-1092. 